\title{
What do community paramedics assess? An environmental scan and content analysis of patient assessment in community paramedicine
}

\author{
Matthew S. Leyenaar, MA*†;; Brent McLeod, MPH, MHM ${ }^{\ddagger \S \ddagger \ddagger ; ~ S a r a h ~ P e n h e a r o w, ~ B S c ~}$; Ryan Strum, \\ HBSc, BA* ${ }^{*}$; Madison Brydges, $\mathrm{MA}^{* *}$; Eric Mercier, MD, $\mathrm{MSc}^{\dagger+}$; Audrey-Anne Brousseau, MD, MSc ${ }^{\neq \neq}$; \\ Floyd Besserer, MD, MS, DMM ${ }^{\ddagger \ddagger \S \S ; ~ G i n a ~ A g a r w a l, ~ M B B S, ~ P h D ~}{ }^{* * * \neq \neq}$; Walter Tavares, PhD IT $^{* * *+\dagger+;}$;

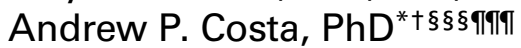

\begin{abstract}
CLINICIAN'S CAPSULE
What is known about the topic?

Community paramedics perform patient assessments to establish physical and psychosocial health, care needs, and health risks at intake.

What did this study ask?

What is assessed in community paramedicine home visit programs at intake, and does it vary across paramedic services?

What did this study find?

We found a wide range of assessment practices suggesting that there may be inconsistencies in care planning and resources across services.

Why does this study matter to clinicians?

Community paramedic training and practice guidelines can build from standardized descriptions of assessment practices to help avoid inconsistent patient care.
\end{abstract}

\section{ABSTRACT}

Objectives: Patient assessment is a fundamental feature of community paramedicine, but the absence of a recognized standard for assessment practices contributes to uncertainty about what drives care planning and treatment decisions. Our objective was to summarize the content of assessment instruments and describe the state of current practice in community paramedicine home visit programs.

Methods: We performed an environmental scan of all community paramedicine programs in Ontario, Canada, and used content analysis to describe current assessment practices in home visit programs. The International Classification on Functioning, Disability, and Health (ICF) was used to categorize and compare assessments. Each item within each assessment form was classified according to the ICF taxonomy. Results: A total of 43 of 52 paramedic services in Ontario, Canada, participated in the environmental scan with 24 being eligible for further investigation through content analysis of intake assessment forms. Among the 24 services, 16 met inclusion criteria for content analysis. Assessment forms contained between 13 and 252 assessment items (median 116.5, IQR 134.5). Most assessments included some content from each of the domains outlined in the ICF. At the subdomain level, only assessment of impairments of the functions of the cardiovascular, hematological, immunological, and respiratory systems appeared in all assessments.

Conclusion: Although community paramedicine home visit programs may differ in design and aim, all complete multidomain assessments as part of patient intake. If community paramedicine home visit programs share similar characteristics but assess patients differently, it is difficult to expect that the resulting referrals, care planning, treatments, or interventions will be similar.

From the *Department of Health Research Methods, Evidence, and Impact, McMaster University, Hamilton, ON; †Ontario Community Paramedicine (Secretariat), ON; ¥Hamilton Niagara Haldimand Brant Local Health Integration Network, Grimsby, ON; §Hamilton Paramedic Service, Hamilton, ON; ๆDepartment of Kinesiology, University of Waterloo, Waterloo, ON; **Department of Health, Aging and Society, McMaster University, Hamilton, ON; ††Département de Médecine Familiale et Médecine d'Urgence, Faculté de Médecine de l'Université Laval, Quebec, QC; $¥ ¥$ Centre Hospitalier Universitaire de Sherbrooke, University of British Columbia, Vancouver, BC; §§British Columbia Emergency Health Services, Vancouver, BC; ITTThe Wilson Centre and Post MD Education, Faculty of Medicine, University of Toronto, Toronto, ON; ***Institute of Health Policy, Management and Evaluation, Dalla Lana School of Public Health, University of Toronto, Toronto, ON; †††York Region Paramedic and Senior Services, Regional

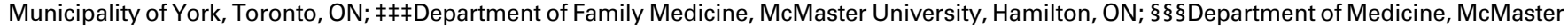
University, Hamilton, ON; and the ITाTCentre for Health Economics and Policy Analysis (CHEPA), McMaster University, Hamilton, ON.

Correspondence to: Matthew S. Leyenaar, McMaster University CRL-219, 1280 Main St. W., Hamilton, ON L8S 4K1; Email: leyenam @mcmaster.ca 


\section{RÉSUMÉ}

Objectifs: L'évaluation des patients est un élément fondamental de la pratique de la paramédecine communautaire, mais l'absence de norme reconnue en matière d'évaluation contribue à l'incertitude qui plane sur les facteurs pris en considération dans la planification des soins et les prises de décision relatives au traitement. L'étude visait donc à présenter un résumé du contenu des instruments d'évaluation et à décrire l'état de la pratique actuelle dans les programmes de visites à domicile en paramédecine communautaire.

Méthode: L'étude consistait en une analyse environnementale de tous les programmes de paramédecine communautaire offerts en Ontario et en une analyse de contenu visant à décrire les pratiques actuelles d'évaluation des patients appliquées dans le cadre des programmes de visites à domicile. Les chercheurs se sont référés à la Classification internationale du fonctionnement, du handicap et de la santé (CIF) pour comparer et classer les évaluations, et chacun des éléments inscrits sur chaque formulaire d'évaluation a été classé selon la taxonomie de la CIF.

Résultats: Au total, 43 services paramédicaux sur 52, en Ontario, ont participé à l'analyse environnementale, dont 24 se prêtaient à une recherche approfondie reposant sur une analyse de contenu des formulaires d'évaluation initiale. Sur les 24 services, 16 répondaient aux critères de sélection en vue d'une analyse de contenu. Le nombre d'éléments évalués variait de 13 à 252 selon les formulaires (médiane : 116,5; écart interquartile : 134,5). La plupart des questionnaires contenaient des éléments tirés de chacun des domaines inscrits dans la CIF. Au niveau des sous-domaines, seule l'évaluation des troubles de fonctionnement des systèmes cardiovasculaire, sanguin, immunitaire et respiratoire figuraient sur tous les formulaires.

Conclusion: Les programmes de visites à domicile en paramédecine communautaire peuvent certes avoir des différences de conception et de but, mais ils permettent tous une évaluation pluridimensionnelle des nouveaux patients. Si les programmes de visites à domicile en paramédecine communautaire ont des caractéristiques communes mais des formes d'évaluation différentes, il est difficile de s'attendre à des résultats comparables en ce qui concerne les consultations, les plans de soins, les traitements et les interventions.

Keywords: Care planning, community paramedicine, content analysis, emergency medical services, environmental scan, patient assessment, patient-care management

\section{INTRODUCTION}

Community paramedicine provides patients with access to scheduled or immediate healthcare in collaboration with other providers across the continuum of care. ${ }^{1}$ Community paramedicine programs are alternatives to traditional ambulance response and transport ${ }^{2-6}$ and aim to address overburdened emergency departments (ED) and fragmented primary care. They are broadly described by their activities, such as supporting transitions from the ED (e.g., hospital to home), assessing and referring to community-based programs, and providing direct preventive care and chronic disease management support. ${ }^{7-10}$ Growing evidence supports the effectiveness of community paramedicine programs in reducing 9-1-1 calls, improving chronic disease management, and enhancing access to community-based care. ${ }^{7-9,11}$ Despite growing evidence and funding, community paramedicine programs raise important questions about training, knowledge base, consistency of care, scope of care, and paramedic roles in the larger healthcare system. $3,4,6,12,13$

In the course of their duties, community paramedics perform patient assessments - often in a patient's home - to establish physical, psychological, and psychosocial healthcare needs and risks that may have negative impacts on patient health. ${ }^{9-11,14-17}$ Assessment is the basis for determining an appropriate course of action, such as initiating preventive care, treatment, and/or referral. Community paramedics can identify patient health needs that may only be apparent in the home, including neglect and abuse $\mathrm{e}^{18,19}$ and other safety concerns. What is assessed in any patient interaction is closely related to paramedic education and clinical training, thus serving as the basis to guide practice. ${ }^{18}$ Minimal available information on the assessment content and practices of community paramedicine programs limits training and development of care guidelines.

Our objective was to inspect and summarize the content of assessment instruments used at time of patient intake or enrolment in community paramedicine home visit programs to inform efforts to evolve community paramedicine program evaluation, training, continuing education, and care guidelines. We hypothesized that the content of community paramedicine assessments would vary markedly across programs, but that some health domains would be assessed consistently across programs. 


\section{METHODS}

\section{Study design}

We conducted an environmental scan and content analysis of community paramedicine home visit programs in Ontario, Canada, between December 4, 2017, and March 15, 2018. Environmental scans establish a network of healthcare stakeholders and scan the network to better understand policies and practices. ${ }^{20-22}$ Content analysis can be used to draw inferences about documents, picture, audio, and video. ${ }^{23,24}$ Directed content analysis of community paramedicine home visit assessment instruments was used to investigate the state of assessment content across programs. ${ }^{25}$ This study was exempt from formal review by the Hamilton Integrated Research Ethics Board based on the lack of direct human participant data collection and low risk.

\section{Setting}

We selected the province of Ontario in Canada to conduct the environmental scan given that it has a growing elderly population, ${ }^{26}$ a fragmented primary care structure, ${ }^{27,28}$ and we were aware that community paramedicine programs have been implemented across the province by many of the 52 paramedic services. In Ontario, community paramedicine programs are eligible for funding through Local Health Integration Networks (LHIN), which are regional administrative organizations of the Ministry of Health and Long-term Care responsible for funding hospitals, long-term care, and home and community care. In isolated instances, paramedic services may initiate community paramedicine programming through other funding sources (municipal, third-party grants, other healthcare partners). There are no mandated or regulated criteria for training, education, or certification for community paramedics. Both primary care and advanced care paramedics may be used to staff community paramedicine programs and conduct patient assessments. We focused on home visit programs given that they are a broadly implemented community paramedicine care model, target similar patients (frequent 9-1-1 users), and use a formal patient assessment at intake. Generalizations of assessment practices across other models of community paramedicine (such as referral or clinic-based programs) would be limited by a relatively small number of comparisons.

\section{Data collection}

A short questionnaire was used to determine basic characteristics of community paramedicine programming at each paramedic service (see Box 1). Two investigators (ML and BM) piloted the questionnaire on three services each and revised it after discussing initial responses. The questionnaire was used to request a blank copy of the intake assessment form used for each service's home visit programs (if services operated such a program). We obtained a list of all paramedic services from a roster of recent invitees to a provincial Community Paramedicine Forum (including management, providers, and administrative support) and then contacted each by phone. When required, voicemail messages were left, and follow-up email correspondence was sent. Our protocol stipulated that multiple attempts should be made to provide paramedic services with adequate opportunity to answer questions about their community paramedicine programs and to achieve a minimal response rate of $80 \%$ for the environmental scan. Responses were recorded in a securely shared Google form (G Suite for Education, Menlo Park, CA, 2018). Three reminder emails were sent to paramedic services who indicated that they were willing to share their community paramedicine assessment forms but had not done so.

\section{Content analysis}

Our content analysis used the International Classification of Functioning, Disability, and Health (ICF), an internationally recognized taxonomy and common language for patient assessment content. The ICF, together with the International Classification of Diseases (ICD), form the Family of International Classifications of the World Health Organization. ${ }^{30}$ The ICF is a hierarchical taxonomy that categorizes individual assessment items into discrete domains and subdomains. ${ }^{31}$ It includes four primary domains (Impairments of Body Functions, Impairments of Body Structures, Activity Limitations and Participation Restriction, and Environmental Factors) as well as Demographic Information. ${ }^{31}$ Demographic Information can include pertinent information about social factors and fits within the ICF framework for providing context to the biopsychosocial model of classification. The domain, Impairments of Body Functions, for example, is divided into subdomains based on the body system involved (mental functions, sensory functions and pain, 
Box 1. Content of the questionnaire used to conduct an environmental scan

1. Service name, contact name, contact position

2. Which statement best reflects community paramedicine programming in your service?

a. Currently providing, no plans for future expansion in the coming year

b. Currently providing, and planning future expansion in the coming year

c. Planning to implement in the coming year, but not presently providing

d. Not providing and not planning to provide in the coming year

3. If community paramedicine programming is presently implemented, which statement best reflects the type of $\operatorname{program}(\mathrm{s})$ ?

a. Referral program (referral to care provided by other organizations)

b. Clinic-based program

c. Home visit program with remote patient monitoring (example: CPRPM $^{29}$ )

d. Home visit program without remote patient monitoring

e. Other

4. If you are planning new or additional community paramedicine programming, which statement best reflects the type of program(s)?
a. Referral program
b. Clinic-based program c. Home visit program with remote patient
monitoring
d. Home visit program without remote patient monitoring
e. Other

5. In general terms, what level of priority does community paramedicine have in your service?

6. Are you willing to share your home visit intake assessment form?

voice and speech functions, and so on). Each subdomain is further divided into categories according to specific functions of the specific system. For example, mental functions is further divided into specific categories such as consciousness, orientation, memory, and language (to name a few). Content from each of the assessment forms was classified at the category level, but for the purposes of this study, results were reported at the domain and subdomain levels to aid in comparison. We used a deductive approach to categorize paramedic assessment forms with the ICF by classifying each assessment item in each form according to the ICF. ${ }^{23}$

Three reviewers with expertise in assessment practices (ML, BM, AC) completed the content analysis. The most comprehensive community paramedicine assessment form was used to calibrate processes for classification between the reviewers. Each blank fillable field was considered an assessment item, except where logic dictated that a field would not be filled (i.e., No Known Allergies [NKA] and a list containing medications such as aspirin, penicillin, sulfa). Any items that were determined to not fit within the ICF framework were then classified as "other." After completing the calibration meeting, two reviewers (ML, BM) conducted content analysis independently following the same approach on all remaining assessment forms. Any items that were classified as "other" were then grouped together under descriptive headings and assigned to an ICF domain. An adjudication meeting was held to resolve any differences in classification by the third reviewer (AC), providing a final classification for all assessment items for all assessment forms. Agreement rates were calculated for the content analysed independently by the two reviewers against the final classification. Basic descriptive statistics were used to report the findings.

\section{RESULTS}

Responses from 43 of 52 paramedic services were received to achieve the predetermined response rate for the environmental scan of $80 \%$. Non-responding paramedic services were from a mix of urban and rural areas and of varying sizes. Respondents represented a variety of job classifications from chief to front-line community paramedic. Responses to the level of priority community paramedicine held within a service were mixed. Thirty-seven $(86 \%)$ paramedic services indicated that they were operating a community paramedicine program, and 28 indicated that they were planning expansion in the coming year. Twenty-six $(70 \%)$ paramedic services indicated that they provided a home visit 


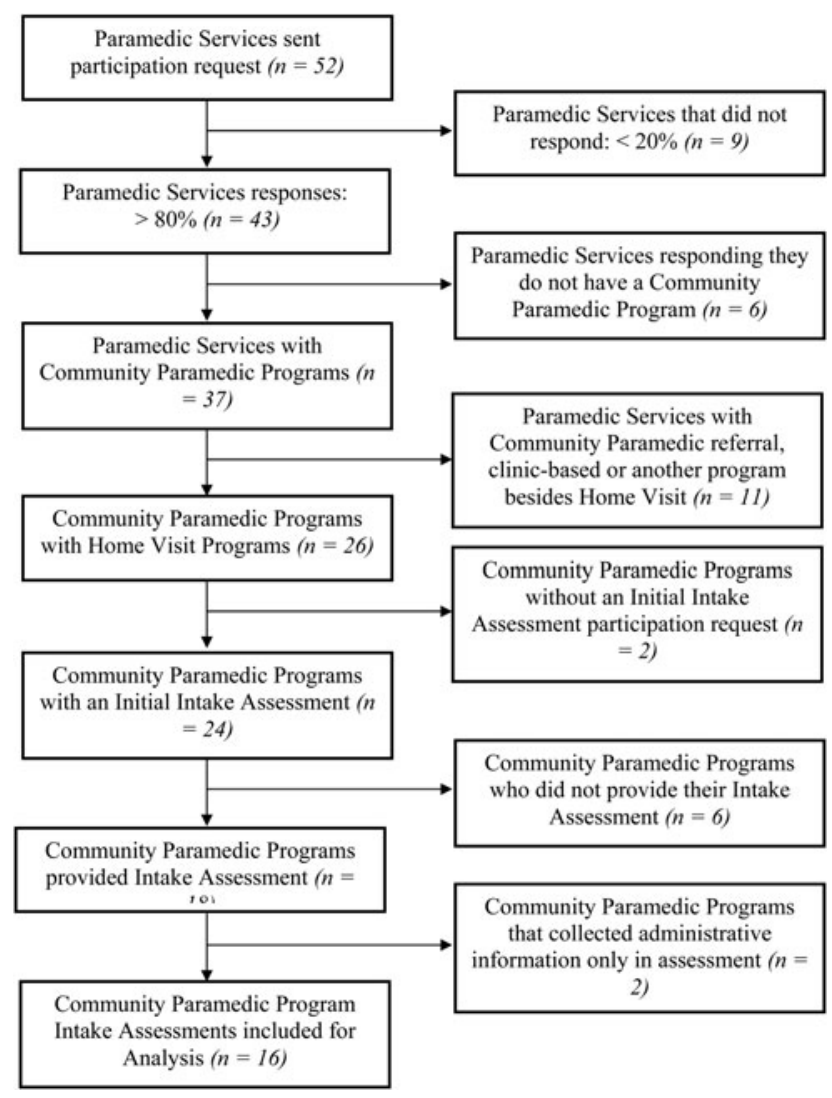

Figure 1. Flowchart illustrating results of environmental scan that produced 16 intake assessment forms for content analysis.

program. Of the 26 paramedic services, 24 (92\%) indicated that they used a formal intake assessment, with 18 of $26(69 \%)$ providing their intake assessment forms for content analysis. After preliminary screening, it was determined that two forms were actually intake forms that contained solely administrative information from outside referring agencies. Sixteen assessment forms were included for content analysis (Figure 1).

Thirteen assessment forms were either paper-based or fillable PDF format, and three were provided as screenshots from electronic forms. Assessment forms contained between 13 and 252 assessment items (median 116.5, IQR 134.5) (see Appendix A, Table 1). Two assessment forms were exact matches for content.

The agreement percentage at the domain and subdomain levels was high for both raters against the final classification. Rater 1 agreed with the final classification $99.0 \%$ and $95.1 \%$ of the time at the domain and subdomain levels, respectively. Rater 2 agreed with the final classification $92.6 \%$ and $89.1 \%$ of the time at the domain and subdomain levels, respectively. Kappa was not calculated because of the adjudication process; we were not interested in the two independent reviewers' agreement with each other, but with the final classification that was discussed (biasing the element of chance).

At the domain level, all assessments included Demographic Information and assessment of Impairments of Body Functions (relating to different organ systems). Fifteen assessments included the assessment of Environmental Factors (such as physical living conditions or information about social supports). Fourteen assessments (88\%) included the assessment of Impairments of Body Structures (relating to different organ systems) and assessment of Activity Limitations and Participation Restriction (such as exercise, hobbies, or taking care of one's health). Appendix A (published as supplementary material online) includes a summary of content within ICF domains and subdomains across community paramedicine home visit assessments.

Most assessments included multiple items classified within multiple subdomains of Impairments of Body Functions. All community paramedicine assessments included function of the cardiovascular, hematological, immunological or respiratory systems, whereas no assessments specifically assessed voice and speech function or functions of the skin and related structures and only one included neuromusculoskeletal and movement-related functions. For any specific subdomain of Impairments of Body Structures, less than half of the community paramedicine assessments included content, and the median number of items within this domain was 3.5 - lowest for any of the four domains. Within the Activity Limitations and Participation Restriction domain, the subdomains with the greatest amount of content were items classified under either mobility or self-care. Environmental Factors was the domain with the highest median number of items, 25. The subdomains within Environmental Factors that had the greatest amount of content were services, systems, and policies, and support and relationships.

Table 1 details the 164 assessment items across the 14 community paramedicine programs that could not be classified at the category level within the ICF (classified as Other). Items were assigned to the closest acceptable ICF domain wherever possible with any remaining items remaining with as a separate Other group. A median of nine items could not be classified for each assessment across three identified domains, Demographic Information, Activity Limitation and Participation Restriction, and Environmental Factors or the separate Other 


\begin{tabular}{|c|c|c|c|c|c|c|c|c|c|c|c|c|c|c|c|c|c|c|c|}
\hline \multirow[b]{2}{*}{ ICF domain } & \multirow[b]{2}{*}{ Other group } & \multicolumn{16}{|c|}{ Community paramedicine program } & \multirow[b]{2}{*}{ Median* } & \multirow{2}{*}{$\begin{array}{l}\text { Programs } \\
\text { assessing } \\
\text { content, } \mathrm{n}(\%)^{\dagger}\end{array}$} \\
\hline & & A & $\mathrm{B}$ & $\mathrm{C}$ & $\mathrm{D}$ & E & $\mathrm{F}$ & G & $\mathrm{H}$ & 1 & J & K & L & M & $\mathrm{N}$ & $\mathrm{O}$ & $P$ & & \\
\hline \multirow[t]{3}{*}{ Demographics } & Recent immigration & $x$ & $x$ & $x$ & $x$ & $x$ & $x$ & $x$ & $x$ & $x$ & $x$ & $x$ & $x$ & $x$ & 1 & $x$ & $x$ & 0 & $1(6)$ \\
\hline & Ethnicity/culture & $x$ & $x$ & $x$ & $x$ & $x$ & $x$ & $x$ & $x$ & $x$ & $x$ & 1 & $x$ & $x$ & $x$ & $x$ & $x$ & 0 & $1(6)$ \\
\hline & Family medical history & $x$ & $x$ & $x$ & $x$ & $x$ & $x$ & $x$ & $x$ & $x$ & $x$ & 1 & $x$ & 5 & $x$ & 1 & $x$ & 0 & $3(19)$ \\
\hline $\begin{array}{l}\text { Activity limitation and } \\
\text { participation restriction }\end{array}$ & Gambling & $x$ & $x$ & $x$ & $x$ & $x$ & $x$ & $x$ & 3 & $x$ & $x$ & 3 & $x$ & $x$ & $x$ & $x$ & $x$ & 0 & $2(13)$ \\
\hline \multirow[t]{3}{*}{ Environmental factors } & Pets & $x$ & 8 & $x$ & $x$ & $x$ & $x$ & $x$ & $x$ & $x$ & $x$ & $x$ & 3 & $x$ & 1 & 1 & 1 & 0 & $5(31)$ \\
\hline & Co-habitant smoker & $x$ & $x$ & $x$ & 2 & $x$ & $x$ & $x$ & $x$ & $x$ & $x$ & 2 & $x$ & $x$ & $x$ & $x$ & 1 & 0 & $3(19)$ \\
\hline & Co-habitant drinker & $x$ & $x$ & $x$ & 2 & $x$ & $x$ & $x$ & $x$ & $x$ & $x$ & 2 & $x$ & $x$ & $x$ & $x$ & 1 & 0 & $3(19)$ \\
\hline \multirow[t]{3}{*}{ Other } & $\begin{array}{l}\text { Do not resuscitate/ } \\
\text { Advance care } \\
\text { planning }\end{array}$ & 4 & 1 & $x$ & 1 & 1 & $x$ & $x$ & 9 & $x$ & $x$ & 9 & $x$ & $x$ & $x$ & 1 & $x$ & 0 & 7 (44) \\
\hline & Medications & $x$ & $x$ & 1 & 6 & $x$ & 1 & 1 & 16 & $x$ & $x$ & 1 & 6 & 5 & 8 & 2 & 14 & 1 & $11(69)$ \\
\hline & Goals for care & 1 & $x$ & 2 & 1 & $x$ & $x$ & $x$ & 19 & $x$ & $x$ & 15 & $x$ & $x$ & $x$ & $x$ & $x$ & 0 & $5(31)$ \\
\hline Total "other" items & & 5 & 9 & 3 & 12 & 1 & 1 & 1 & 47 & 0 & 0 & 34 & 9 & 10 & 15 & 13 & 17 & 9 & $14(88)$ \\
\hline
\end{tabular}

group. Most prevalent in the separate Other group was information about medications followed by information pertaining to either Do Not Resuscitate or Advance Care Planning.

Table 2 summarizes assessment items found within each ICF subdomain by prevalence across community paramedicine home visit programs. Assessment items classified under a small number of subdomains were found to be highly prevalent. These were items pertaining to functions of the cardiovascular, hematological, immunological, and respiratory systems; mental functions; functions of the digestive, metabolic, and endocrine systems; mobility; self-care; services, systems, and policies; and existing medical diagnoses. Many more assessment items were found to be inconsistently assessed across ICF subdomains. The low prevalence for multiple subdomains is reflected in the bottom two rows of Table 2 .

\section{DISCUSSION}

We found that most ICF assessment domains are being considered to varying lengths and depths in almost all community paramedicine assessments. The fact that some ICF subdomains were assessed in some community paramedicine programs with one or two items, whereas other community paramedicine programs assessed most ICF subdomains with many items, demonstrates this variety. That all of the included community paramedicine programs had assessment items in the ICF subdomain, functions of the cardiovascular, hematological, immunological, and respiratory systems, suggests that patients enrolled in community paramedicine home visit programs likely have a high prevalence of diseases and conditions associated with these systems such as diabetes, heart disease, chronic obstructive pulmonary disease, or congestive heart failure. Examples of these assessment items included basic vital signs and other diagnostics within a primary care paramedic scope of practice, such as pulse oximetry, 12-lead EKG, or blood glucometry. In general, paramedic training and education includes an emphasis on the life-threats associated with these systems, which likely also contributed to the prevalence of assessment items aligned with this subdomain. ${ }^{32}$

\section{Limitations}

Community paramedicine home visit programs are a new service model for paramedic practice with a relative paucity of clinical guidelines to anchor practice. $^{3}$ 


\begin{tabular}{|c|c|c|c|c|c|c|}
\hline & Demographics & $\begin{array}{l}\text { Impairments of Body } \\
\text { Functions }\end{array}$ & $\begin{array}{l}\text { Impairments of } \\
\text { Body Structures }\end{array}$ & $\begin{array}{l}\text { Activity Limitation } \\
\text { and Participation } \\
\text { Restriction }\end{array}$ & $\begin{array}{l}\text { Environmental } \\
\text { Factors }\end{array}$ & Other \\
\hline $\begin{array}{l}\text { Items appeared } \\
\text { in all } \\
\text { assessments }\end{array}$ & $\begin{array}{l}\text { - Name } \\
\text { - Date of birth }\end{array}$ & $\begin{array}{l}\text { - Functions of the } \\
\text { cardiovascular, } \\
\text { hematological, } \\
\text { immunological, and } \\
\text { respiratory systems }\end{array}$ & $x$ & $x$ & $x$ & $x$ \\
\hline $\begin{array}{l}\text { Items appeared } \\
\text { in } \geq 75 \% \text { of } \\
\text { assessments }\end{array}$ & $\begin{array}{l}\text { - Address } \\
\text { - Existing } \\
\text { medical } \\
\text { diagnosis }\end{array}$ & $\begin{array}{l}\text { - Mental functions } \\
\text { - Functions of the } \\
\text { digestive, metabolic, } \\
\text { and endocrine systems }\end{array}$ & $x$ & $\begin{array}{l}\text { Mobility } \\
\text { - Self-care }\end{array}$ & $\begin{array}{l}\text { - Services, } \\
\text { systems, and } \\
\text { policies }\end{array}$ & $x$ \\
\hline $\begin{array}{l}\text { Items appeared } \\
\text { in } \leq 25 \% \text { of } \\
\text { assessments }\end{array}$ & $\begin{array}{l}\text { - Current marital } \\
\text { status }\end{array}$ & $\begin{array}{l}\text { - Neuromusculoskeletal } \\
\text { and movement-related } \\
\text { functions }\end{array}$ & $\begin{array}{l}\text { - Structure of the } \\
\text { nervous system } \\
\text { - The eye, ear, and } \\
\text { related } \\
\text { structures } \\
\text { - Structures related } \\
\text { to the digestive, } \\
\text { metabolism, and } \\
\text { endocrine } \\
\text { systems } \\
\text { - Structure related } \\
\text { to genitourinary } \\
\text { and reproductive } \\
\text { system }\end{array}$ & $\begin{array}{l}\text { - Learning and } \\
\text { applying } \\
\text { knowledge } \\
\text { - Communication } \\
\text { - Interpersonal } \\
\text { interactions and } \\
\text { relationships } \\
\text { - Community, } \\
\text { social, and civic } \\
\text { life }\end{array}$ & $\begin{array}{l}\text { - Natural } \\
\text { environment } \\
\text { and human } \\
\text { made changes } \\
\text { to environment } \\
\text { - Attitudes }\end{array}$ & $\begin{array}{l}\text { - Recent } \\
\text { immigration } \\
\text { - Ethnicity/ } \\
\text { culture } \\
\text { - Family } \\
\text { medical } \\
\text { history } \\
\text { - Gambling } \\
\text { - Co-habitant } \\
\text { smoker } \\
\text { - Co-habitant } \\
\text { drinker }\end{array}$ \\
\hline $\begin{array}{l}\text { Items appeared } \\
\text { in no } \\
\text { assessments }\end{array}$ & $\begin{array}{l}\text { - Years of formal } \\
\text { education } \\
\text { - Current } \\
\text { occupation }\end{array}$ & $\begin{array}{l}\text { - Voice and speech } \\
\text { functions } \\
\text { - Functions of the skin and } \\
\text { related structures }\end{array}$ & $\begin{array}{l}\text { - Structures } \\
\text { involved in voice } \\
\text { and speech }\end{array}$ & $\begin{array}{l}\text { - General tasks and } \\
\text { demands }\end{array}$ & $x$ & $x$ \\
\hline
\end{tabular}

Determining the state of current community paramedicine assessment practice through an investigation of intake assessment forms using content analysis relies on certain assumptions about documentation standards and quality assurance processes, which have not necessarily been formalized. By using the ICF as a mechanism to classify content, we also assumed that some baseline criteria for assessment practice could be identified between different paramedic services that may employ paramedics with differing scopes of practice or whose community paramedicine programs may have different designs or objectives. One characteristic of community paramedicine programs is that they are designed in response to locally identified needs, ${ }^{3,4,13}$ meaning that finding differences in assessment practices would be likely. Although this suggests that inherent differences should be expected, a recent review of case management and care planning in community paramedicine home visit programs found that common attributes existed in the patient populations served by these programs across multiple jurisdictions. ${ }^{13}$ Although our study was conducted in one province only, sampling 16 different community paramedicine home visit programs likely demonstrates that many of the differences in the scope of paramedic practice and in program design would be expected in a national sample.

Our content analysis of assessment items is an investigation of the opportunity to document assessment findings. It is assumed that the intake assessment conducted by a community paramedic in a home visit program should be completed in full and would be comprehensive enough to direct subsequent care planning without requiring secondary or subsequent assessment. Formalizing the assessment training process for community 
paramedics and developing assessment guidelines may address whether or not this is true. Even so, differences between community paramedicine program assessments at the subdomain level were observed in many areas. For example, falls prevention is a common focus of community paramedicine programs. ${ }^{1}$ Falls prevention is a complex and multi-faceted approach where the benefits of assessment of falls risk have been demonstrated. ${ }^{33} \mathrm{We}$ found that most community paramedicine home visit programs included an assessment of mobility (see Table 2), suggesting a consistency of focus in this area. However, only one of the community paramedicine home visit programs assessed structures related to the genitourinary and reproductive system and genitourinary and reproductive functions. Urinary incontinence is associated with increased odds of falling ${ }^{34-37}$ and has been identified as an area of falls prevention programs that requires improved assessment and surveillance, ${ }^{33}$ which means that it is a strong area for guideline development and education in the future. Determining whether or not assessment of continence should or should not be assessed by community paramedics requires further inquiry. Similar arguments can be made about the rationale for many of the ICF subdomains where items were not assessed consistently across the community paramedicine home visit programs that participated in our study. If community paramedics are indiscriminately conducting assessments based on ICF subdomains that they perceive as valuable without evidence informed guidelines or education, then it is possible that some may be missing out on key areas that may help them achieve their intended goals for care.

\section{Implications}

Community paramedicine home visit assessment forms vary in depth, suggesting that assessment practices and, potentially, care vary across services sampled in Ontario. Previously published studies about community paramedicine programs in Ontario ${ }^{10,15}$ suggest that specific program aims likely contribute to this variation. But, if community paramedicine home visit programs do share similar characteristics (in terms of population served and goals for care), yet assess patients differently, it is difficult to expect that the resulting referrals, care planning, treatments, or interventions will be similar. In turn, such differences will also likely result in inequalities in patient care between different locations. General health assessment practices have evolved to consider multiple disease processes across multiple care settings with the ability to integrate with other care providers ${ }^{38}$ - all criteria that should guide assessment practices in community paramedicine because patient assessment is foundational to managing care plans, collaborating with other care providers, and providing interventions. ${ }^{39-41}$ The importance of assessment has been demonstrated in traditional paramedic practice ${ }^{41}$ and often underlies program delivery in community paramedicine., ${ }^{3,4,13,18}$ Future work regarding the minimum threshold for intake assessments in community paramedicine home visit programs should engage stakeholders to determine the appropriateness of the assessment areas that have been summarized here.

\section{CONCLUSION}

Community paramedicine home visit program assessments cover all domains of the ICF, yet the number of assessment items is often limited and highly variable across services. Relative consistency was observed for the assessment of the functions of the cardiovascular, hematological, immunological or respiratory systems. Other commonly assessed subdomains were mental functions; functions of the digestive, metabolic, and endocrine systems; mobility; self-care; and utilization of support services, systems, and policies. Identifying a minimum threshold for patient assessment and consolidating assessment practices could promote the development of community paramedic training and contribute to clinical guidelines for community paramedic practice. By summarizing the content of assessment instruments and describing the state of current practice in community paramedicine home visit programs, it is possible for community paramedicine programs to reflect on specific assessment domains that may be contributing to achieving their goals for patient care.

Acknowledgements: The authors would like to acknowledge the following Ontario paramedic services and thank them for providing content for analysis; County of Brant Ambulance Services, Dufferin County Paramedic Service, Essex-Windsor Emergency Medical Services, Grey County Paramedic Services, Hamilton Paramedic Services, Lambton Emergency Medical Services, Lanark County Paramedic Services, Leeds-Grenville Paramedic Service, Niagara Emergency Medical Services, Norfolk County Paramedic Services, Prescott Russell Paramedic Service, County of Renfrew Paramedic Services, Superior North Emergency Medical Services, Greater Sudbury Paramedic Services, Toronto Paramedic Services, and York Region Paramedic Services.

Competing interests: None declared. 
Prior presentations: 2018 Achieving Excellence Together, Annual Conference of Health Shared Services Ontario, Toronto, ON, June 19, 2018

Funding: ML received support for this research from the Canadian Frailty Network, Mitacs, Canadian Institute for Health Research, and the Hamilton Niagara Haldimand Brant Local Health Integration Network (formerly the Hamilton Niagara Haldimand Brant Community Care Access Centre).

Author contributions: ML, AC, and BM conceived the study. $\mathrm{ML}$ and $\mathrm{BM}$ developed and performed the survey. SP managed survey responses and follow-up. ML, AC, and BM performed the content analysis. ML prepared the first draft of the manuscript. All authors contributed substantially to the design and methodology of the study and to the writing and critical editing of this manuscript.

\section{SUPPLEMENTARY MATERIAL}

The supplementary material for this article can be found at https://doi.org/10.1017/cem.2019.379

\section{REFERENCES}

1. CSA Group. Community paramedicine: framework for program development. Toronto, ON: CSA Group; 2017.

2. Jensen JL, Carter AJE, Rose J, et al. Alternatives to traditional EMS dispatch and transport: a scoping review of reported outcomes. CFEM 2015;17(5):532-50.

3. Bigham BL, Kennedy SM, Drennan I, Morrison LJ. Expanding paramedic scope of practice in the community: a systematic review of the literature. Prehosp Emerg Care 2013;17 (3):361-72.

4. O'Meara P. Community paramedics: a scoping review of their emergence and potential impact. Int Paramed Pract 2014;4(1):5-12.

5. Iezzoni LI, Dorner SC, Ajayi T. Community paramedicineaddressing questions as programs expand. $N$ Engl $7 \mathrm{Med}$ 2016;374(12):1107-9.

6. Choi BY, Blumberg C, Williams K. Mobile integrated health care and community paramedicine: an emerging emergency medical services concept. Ann Emerg Med 2016;67(3):361-6.

7. Lau HS, Hollander MM, Cushman JT, et al. Qualitative evaluation of the coach training within a community paramedicine care transitions intervention. Prehosp Emerg Care 2018;22(4):527-34.

8. Verma AA, Klich J, Thurston A, et al. Paramedic-initiated home care referrals and use of home care and emergency medical services. Prehosp Emerg Care 2017;0(0):1-6.

9. Agarwal G, McDonough B, Angeles R, et al. Rationale and methods of a multicentre randomised controlled trial of the effectiveness of a Community Health Assessment Programme with Emergency Medical Services (CHAP-EMS) implemented on residents aged 55 years and older in subsidised seniors' housing. BMF Open 2015;5(6):1-7
10. Drennan IR, Dainty KN, Hoogeveen P, et al. Expanding paramedicine in the community (EPIC): study protocol for a randomized controlled trial. Trials 2014;15(473):1-10.

11. Abrashkin KA, Washko J, Zhang J, et al. Providing acute care at home: community paramedics enhance an advanced illness management program - preliminary data. $7 \mathrm{Am}$ Geriatr Soc 2016;64(12):2572-6.

12. Newsroom: Ontario expanding community role for paramedics; 2014. Available at: https://news.ontario.ca/mohltc/en/ 2014/01/ontario-expanding-community-role-for-paramedics.html (accessed August 20, 2018).

13. Leyenaar M, Mcleod B, Chan J, et al. A scoping study and qualitative assessment of care planning and case management in community paramedicine. Irish 7 Paramed 2018;3:1-15.

14. Crockett BM, Jasiak KD, Walroth TA, et al. Pharmacist involvement in a community paramedicine team; 2016. Available at: http://jpp.sagepub.com/cgi/doi/10.1177/ 0897190016631893 (accessed December 28, 2016).

15. Ruest M, Stitchman A, Day C. Evaluating the impact on 911 calls by an in-home programme with a multidisciplinary team. Int Paramed Pract 2012;1(4):125-32.

16. Swain AH, Hoyle SR, Long AW. The changing face of prehospital care in New Zealand: the role of extended care paramedics. 7 New Zeal Med Assoc 2010;19(123):1-14.

17. Mason S, Wardrope J, Perrin J. Developing a community paramedic practitioner intermediate care support scheme for older people with minor conditions. Emerg Med 7 2003;20(2):196-8.

18. O'Meara P, Stirling C, Ruest M. Community paramedicine model of care: an observational, ethnographic case study. BMC Health Serv Res 2016;16(1):39.

19. Rosen T, Lien C, Stern ME, et al. Emergency medical services perspectives on identifying and reporting victims of elder abuse, neglect, and self-neglect. 7 Emerg Med 2017;53(4):573-82.

20. Hatch TF, Pearson TG. Using environmental scans in educational needs assessment. $\mathcal{f}$ Contin Educ Health Prof 1998;18(3):179-84.

21. Rowel R, Dewberry Moore N, Nowrojee S, et al. The utility of the environmental scan for public health practice: lessons from an urban program to increase cancer screening. $7 \mathrm{Natl}$ Med Assoc 2005;97(4):527-34.

22. Graham P, Evitts T, Thomas-MacLean R. Environmental scans: how useful are they for primary care research? Can Fam Physician 2008;54(7):1022-3.

23. Krippendorff K. Content analysis. In International encyclopedia of communications. Oxford University Press; 1989, 403-7. Available at: http://repository.upenn.edu/asc_papers/ 226 (accessed August 10, 2017).

24. Elo S, Kyngäs $H$. The qualitative content analysis process. 7 Adv Nurs 2008;62(1):107-15.

25. Hsieh H-F, Shannon SE. Three approaches to qualitative content analysis. Qual Health Res 2005;15(9):1277-88.

26. Canada. Population projections for Canada, provinces and territories; 2009. Available at: https://www150.statcan.gc.ca/ n1/pub/91-520-x/91-520-x2010001-eng.htm (accessed October 10, 2018).

27. Ontario Ministry of Health and Long-Term Care. Patients first: a proposal to strengthen patient-centred health care in Ontario; 2015, 1-24. Available at: http://www.health.gov. 
on.ca/en/news/bulletin/2015/docs/discussion_paper_20151217. pdf (accessed October 10, 2018).

28. Marchildon GP, Hutchison B. Primary care in Ontario, Canada: new proposals after 15 years of reform. Health policy (New York). Sci Direct 2016;120(7):732-8.

29. Brohman M, Green M, Dixon J, et al. Community paramedicine remote patient monitoring (CPRPM): benefits evaluation and lessons learned. Toronto, ON: ; 2018. Available at: https://infoway-inforoute.ca/en/what-we-do/news-events/ webinars/resources/reports/benefits-evaluation/3542-community-paramedicine-remote-patient-monitoring-cprpmbenefits-evaluation-lessons-learned (accessed April 23, 2018).

30. World Health Organization. WHO Family of International Classifications (WHO-FIC); 2018. Available at: http:// www.who.int/classifications/en/ (accessed August 20, 2018).

31. Towards a common language for functioning, disability and health ICF.: Geneva, Switzerland: World Health Organization; 2002.

32. Paramedic Association of Canada. National occupational competency profile for paramedics; 2011. Available at: http://www.paramedic.ca/uploaded/web/documents/201110-31-Approved-NOCP-English-Master.pdf (accessed April 8, 2019).

33. Gillespie LD, Robertson MC, Gillespie WJ, et al. Interventions for preventing falls in older people living in the community. Cochrane Database Syst Rev 2012;2(CD007146): CD007146.
34. Chiarelli PE, Mackenzie LA, Osmotherly PG. Urinary incontinence is associated with an increase in falls: a systematic review. Aust 7 Physiother 2009;55(2):89-95.

35. Gale CR, Cooper C, Aihie Sayer A. Prevalence and risk factors for falls in older men and women: the English longitudinal study of ageing. Age Ageing 2016;45(6):789-94.

36. Szabo SM, Gooch KL, Walker DR, et al. The association between overactive bladder and falls and fractures: a systematic review. Advances in Therapy 2018; 35(11):1831-41.

37. Noguchi N, Chan L, Cumming RG, et al. A systematic review of the association between lower urinary tract symptoms and falls, injuries, and fractures in community-dwelling older men. Aging Male 2016;19(3):168-74.

38. Wellens NIH, Deschodt M, Flamaing J, et al. Firstgeneration versus third-generation comprehensive geriatric assessment instruments in the acute hospital setting: a comparison of the Minimum Geriatric Screening Tools (MGST) and the interRAI Acute Care (interRAI AC). $\mathcal{7}$ Nutr Health Aging 2011;15(8):638-44.

39. Wears RL. Introduction: The Approach to the Patient in the Emergency Department. In: Harwood-Nuss' clinical practice of emergency medicine (ed. Wolfson AB). 6th ed. Philadelphia, PA: Lippincott Williams \& Wilkins; 2015.

40. Brennan J, Krohmer J. Principles of EMS systems. Sudbury, MA: Jones \& Bartlett Learning; 2006.

41. Colbeck MA, Maria S, Eaton G, et al. International examination and synthesis of the primary and secondary surveys in paramedicine. Irish 7 Paramed 2018;3(2):1-9. 